\title{
ANALISIS KEANEKARAGAMAN JENIS POHON SEBAGAI SALAH SATU INDIKATOR KESEHATAN HUTAN KONSERVASI
}

\author{
Analysis of Tree Diversity as An Indicator of The Health of Conservation Forests \\ Rahmat Safe'i ${ }^{1 凶}$, Hasbiyan Erly², Christine Wulandari' ${ }^{1}$ Hari Kaskoyo ${ }^{1}$ \\ 1Program Studi Magister Ilmu Kehutanan, Fakultas Pertanian, Universitas Lampung \\ JI. Prof. Dr. Soemantri Brodjonegoro No. 1 Bandar Lampung 35145 \\ 2Mahasiswa Program Studi Magister IImu Kehutanan, Fakultas Pertanian, Universitas Lampung \\ JI. Prof. Dr. Soemantri Brodjonegoro No. 1 Bandar Lampung 35145 \\ ${ }^{\square}$ corresponding author: mat_ane@yahoo.com
}

\begin{abstract}
The Bukit Barisan Selatan National Park area (TNBBS) has a complete ecosystem ranging from coastal ecosystems, lowland rainforests to mountain rainforests as well as high potential of living natural and non-biological resources. One of the key ecological indicators for the health of tropical rainforests is biodiversity. The ecological stability level of BBSNP will be influenced by the diversity of ecological functions where the higher the value of diversity of tree species will also increase the level of ecological stability. So that the diversity of tree species is used as a measurable indicator of biodiversity. This study aims to determine the value of forest health with indicators of tree species diversity in Biha, Ngambur, and Bleeding in BBSNP. The research was carried out at Biha, Ngambur, and Pemihan Resorts by assessing forest health using the Forest Health Monitoring (FHM) method. The research was carried out in stages which consisted of setting and making plot clusters, measuring biodiversity indicators, processing and analyzing data, and assessing forest health. The results of the study showed that the value of tree species diversity average in Resort Biha, Ngambur and Bleeding was very stabile with a value of $\mathrm{H}^{\prime}>2$. Health assessment The results of the study showed that the value of forest health status in TNNBS was in poor criteria (cluster plot-5), medium (cluster plot-1, 2, and 3), and good (cluster plot-4). Thus, the current condition of the forest health status in the Resort National Park TNNBS is on average criteria.
\end{abstract}

Key words: Forest Health Monitoring (FHM); forest health; tree diversity

\section{A. PENDAHULUAN}

Taman nasional adalah kawasan pelestarian alam yang mempunyai ekosistem asli, dikelola dengan sistem zonasi yang dimanfaatkan untuk tujuan penelitian, ilmu pengetahun, pendidikan, menunjang budidaya, pariwisata, dan rekreasi (Undang-Undang Nomor 5 tahun 1990). Salah satu dari lima puluh taman nasional yang ada di Indonesia adalah Taman Nasional Bukit Barisan Selatan (TNBBS) yang terletak di ujung wilayah barat daya Sumatera yang berada di dua Provinsi yaitu Provinsi Bengkulu dan Provinsi Lampung.

Wilayah TNBBS memiliki tingkat biodiversitas yang cukup tinggi, diantaranya keanekagaman jenis pohon. Menurut Safe'i et al. (2013), kesehatan hutan TNBBS bisa dinilai melalui keanekaragaman jenis pohon yang diidentifikasi sebagai kriteria keberlanjutan ekosistem hutan. Perubahan tutupan lahan dari keadaan berhutan menjadi tidak berhutan mengakibatkan penurunan keanekaragaman hayati (biodiversitas) TNBBS yang mengakibatkan perubahan kesehatan hutan di wilayah TNBBS. Hutan dikatakan sehat apabila hutan tersebut masih dapat memenuhi fungsinya sebagaimana fungsi utama yang telah diharapkan sebelumnya yaitu fungsi produksi, lindung dan konservasi (Nuhamara et al., 2001), sehingga kesehatan hutan dapat digambarkan sebagai suatu kondisi dari ekosistem hutan yang mampu menjalankan fungsi utamanya. Dalam segi ekologi, hutan yang sehat adalah hutan yang menunjukkan adanya interaksi yang seimbang antara seluruh komponen yang ada di dalam hutan (Safe'i dan Tsani, 2016). Oleh karena itu, penelitian ini penting dilakukan untuk mengetahui keanekaragaman jenis pohon di TNBBS sebagai salah satu indikator penilaian kesehatan hutan.

\section{B. METODE}

Penelitian ini dilakukan di 13 (tiga belas) klaster plot dalam wilayah Resort Biha, Ngambur, dan Pemerihan yang termasuk dalam SPTN II Bengkunat, BPTN Wilayah I Semaka pada Kawasan Hutan TNBBS, Provinsi Lampung. Penelitian ini dilakukan pada periode bulan Juli s.d. Oktober 2017. Lokasi penelitian dapat dilihat pada Gambar 1. 


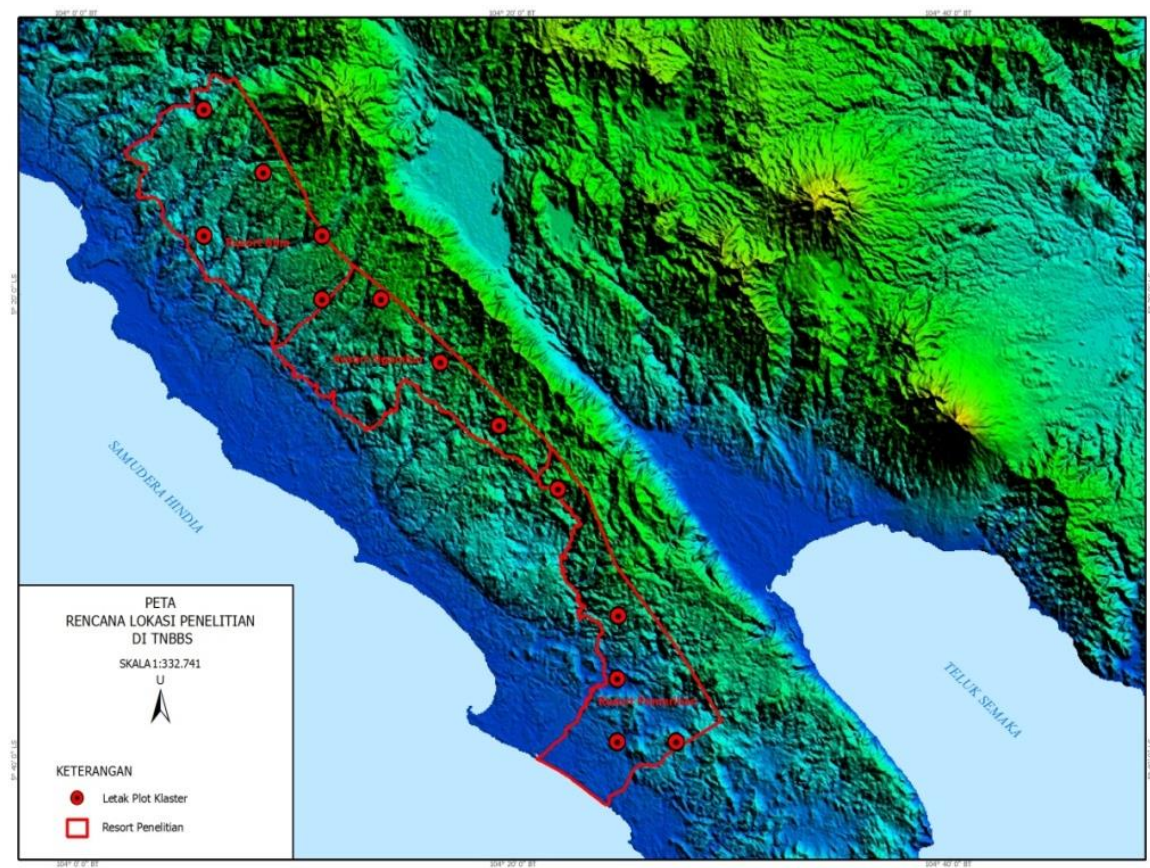

Gambar 1. Peta lokasi penelitian.

\section{Observasi Lokasi Plot Ukur Kesehatan Hutan.}

Observasi dimaksudkan untuk mendapatkan lokasi plot ukur di 13 (tiga belas) plot klaster dalam wilayah Resort Biha, Ngambur, dan Pemerihan yang termasuk dalam SPTN II Bengkunat, BPTN Wilayah I Semaka pada Kawasan Hutan TNBBS, Provinsi Lampung.

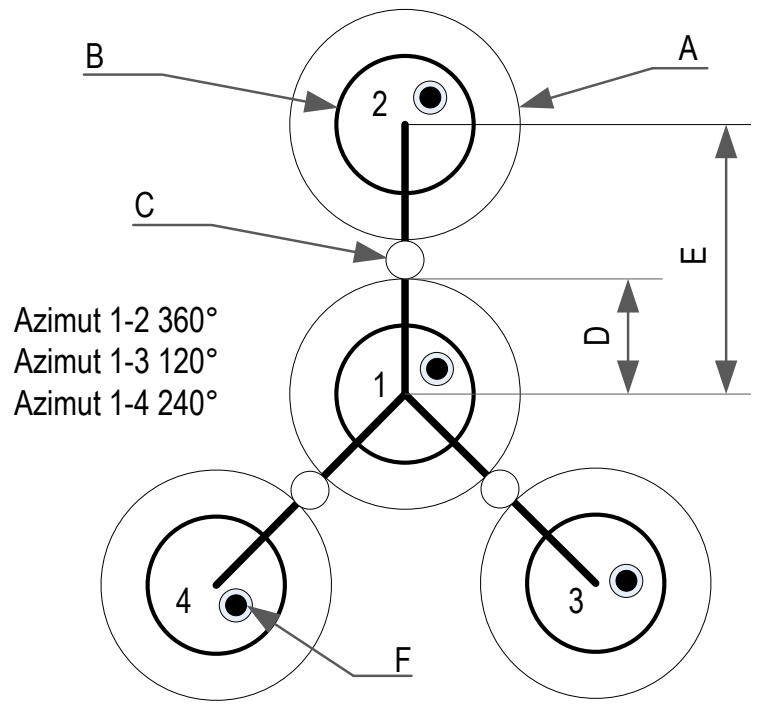

Gambar 2. Desain klaster-plot FHM. Keterangan: $A=$ Annular plot jari-jari 17,95 m; $B=$ subplot jari-jari 7,32 m; $C=$ titik contoh tanah; $\mathrm{D}=$ jarak titik contoh tanah dari titik pusat subplot adalah $18 \mathrm{~m} ; \mathrm{E}=$ jarak antara titik pusat plot adalah $36,6 \mathrm{~m} ; \mathrm{F}=$ mikroplot jari-jari 2,07 m tiap azimut dan jarak dari titik pusat subplot adalah $3,66 \mathrm{~m}$.

\section{Pembuatan Plot Ukur Kesehatan Hutan}

Klaster-plot adalah desain plot contoh yang digunakan dalam pembuatan plot ukur kesehatan hutan pada berbagai tipe hutan. Pembuatan plot ukur kesehatan hutan ini didasarkan pada desain klaster plot FHM (Mangold, 1997; USDA-FS, 1999) sebagaimana disajikan pada Gambar 2.

\section{Pengolahan dan Analisis Data}

Pengolahan dan analisis data dilakukan terhadap hasil pengukuran keanekaragaman pohon di lokasi penelitian. Tingkat keanekaragaman jenis ditentukan menggunakan rumus Shannon-Whiener index $\mathrm{H}^{\prime}$ (Soerianegara dan Indrawan, 2005).

$H^{\prime}=\sum p_{i} \ln p_{i}$

Di mana, $\mathrm{H}^{\prime}$ adalah Indeks keanekaragaman, $\mathrm{p}_{\mathrm{i}}$ adalah $n_{i} / N$, In adalah logaritma natural, $n_{i}$ adalah jumlah individu jenis ke-i, $\mathrm{N}$ adalah jumlah individu seluruh jenis

Jika nilai $H^{\prime}<1$, maka komunitas vegetasi dengan kondisi lingkungan kurang stabil; jika nilai $\mathrm{H}^{\prime}$ antara 1-2, maka komunitas vegetasi dengan kondisi lingkungan stabil; jika nilai H' > 2, maka komunitas vegetasi dengan kondisi lingkungan sangat stabil.

\section{Penilaian Kesehatan Hutan}

Pengukuran kesehatan hutan digunakan satu indikator yaitu keanekaragaman jenis pohon. Data yang diperoleh digunakan untuk mengetahui status kesehatan hutan yang diukur berdasarkan FHM. Kesehatan hutan 
Tabel 1. Keberadaan suku dipterocarpaceae di resort Biha, Ngambur, dan Pemerihan

\begin{tabular}{cccccc}
\hline No & Resort & $\begin{array}{c}\text { Jumlah } \\
\text { Suku }\end{array}$ & $\begin{array}{c}\text { Jumlah } \\
\text { Individu } \\
\text { Dipterocarpaceae }\end{array}$ & $\begin{array}{c}\text { Jumlah Total } \\
\text { Individu }\end{array}$ & $\begin{array}{c}\text { Persentase keberadaan } \\
\text { Individu Dipterocarpaceae } \\
(\%)\end{array}$ \\
\hline 1 & Biha & 35 & 183 & 680 & 26,91 \\
2 & Ngambur & 31 & 63 & 307 & 20,52 \\
3 & Pemerihan & 38 & 237 & 611 & 38,79 \\
& Jumlah & 51 & 483 & 1.598 & \\
\hline
\end{tabular}

diperoleh dari hasil perkalian antara nilai tertimbang dengan nilai skor dari masing-masing indikator kesehatan hutan. Nilai tertimbang merupakan eigen yang diperoleh dengan menggunakan Analysis Networking Process (ANP). Nilai skor didapatkan dari transformasi nilai keanekaragaman jenis pohon di TNBBS. Rumus nilai akhir kesehatan hutan (Safe'i et al., 2015) adalah:

$N K H=N T \times N S$

Di mana, NKH adalah nilai akhir kondisi kesehatan hutan, NT adalah nilai tertimbang parameter dari masing-masing indikator kesehatan hutan, NS adalah nilai skor parameter dari masing-masing indikator kesehatan hutan.

\section{HASIL DAN PEMBAHASAN}

Tingkat biodiversitas berbanding lurus dengan tingkat kelenturan, dimana semakin tinggi tingkat biodiversitas yang dimiliki dalam suatu hutan akan meningkatkan tingkat kelenturan hutan. Safe'i dan Tsani (2016) menyatakan bahwa salah satu komponen hayati yang ada di dalam hutan adalah pohon. Jika keanekaragaman hayati mengacu pada seluruh makhluk hidup yang ada di hutan, maka keanekaragaman pohon adalah semua jenis-jenis pohon yang ada di dalam hutan. Hutan alam cenderung secara alami memiliki berbagai macam jenis tanaman. Keanekaragaman jenis tanaman yang tinggi membantu hutan tetap menjaga keseimbangan ekologi. Kajian kelestarian hutan tidak lepas dari keberadaan komunitas tumbuhan atau pohon. Dalam mempelajari komunitas pohon yang ada di dalam hutan, berarti mempelajari tentang struktur dan komposisinya. Struktur dan komposisi komunitas dapat menjelaskan keanekaragaman spesies di dalam hutan.

Pengukuran kesehatan hutan dengan indikator biodiversitas (keanekaragaman pohon) di TNBBS yang diukur hanya pohon-pohon yang berada dalam sub-plot. Biodiversitas sebagai keanekaragaman hidup di bumi, mencakup jutaan spesies tumbuhan, hewan, mikroorganisme; materi genetik yang dikandungnya; serta ekosistem yang dibangun sehingga menjadi sebuah lingkungan hidup (WWF, 1989). Pengukuran dilakukan dengan menggunakan indeks keanekaragaman ShannonWhiener pada 5 klater plot yang mewakili lokasi penelitian.
Berdasarkan hasil penelitian di lapangan diperoleh bahwa rata-rata keberadaan Suku Dipterocarpaceae mendominasi $(30,23 \%)$ dalam ekosistemResort Biha (26,91\%), Ngambur (20,52\%), dan Pemerihan (38,79\%) terhadap individu jenis lainnya sebagaimana dapat dilihat pada tabel 3. Hasil penelitian di Resort Biha, Ngambur, dan Pemerihan sesuai dengan penelitian yang dilakukan oleh Wallace dan Weber (Kusmana dan Hikmat, 2015) bahwa flora di Sumatera termasuk dalam wilayah flora Dataran Sunda yang didominasi oleh jenis tumbuhan berhabitus pohon dari suku Dipterocarpaceae. Berdasarkan Kusmana dan Hikmat (2015), ekosistem di Resort Biha, Ngambur, dan Pemerihan termasuk dalam bioma hutan hujan, sub bioma hutan hujan tanah kering, dan tipe ekosistem Dipterocaparceae campuran karena didominasi suku Dipterocarpaceae dengan ketinggian $<1.000 \mathrm{dpl}$. Penjelasan keberadaan Dipterocarpaceae dapat dilihat pada Tabel 1.

Setelah melakukan penghitungan didapatkan nilai keanekaragam pada setiap resort. Resort Biha mempunyai rata-rata nilai $\mathrm{H}^{\prime}=2,52$. Nilai $\mathrm{H}^{\prime}$ terendah dan nilai $\mathrm{H}^{\prime}$ tertinggi terdapat di klaster plot 3 (tiga) dan klaster plot 1 (satu) yaitu 2,19 dan 2,96. Resort Ngambur mempunyai rata-rata nilai $H^{\prime}=2,72$. Nilai $H^{\prime}$ terendah dan nilai $\mathrm{H}^{\prime}$ tertinggi terdapat di plot klaster 6 (enam) dan plot klaster 8 (delapan) yaitu 2,19 dan 3,07. Resort Pemerihan mempunyai rata-rata nilai $H^{\prime}=2,70$. Nilai $H^{\prime}$ terendah dan nilai $\mathrm{H}^{\prime}$ tertinggi terdapat di klaster plot 13 (tiga belas) dan klaster plot 12 (dua belas) yaitu 1,55 dan 3,82. Berdasarkan Magguran (1988) besaran $H^{\prime}<1,5$ menunjukkan keanekaragaman jenis tergolong rendah, jika $H^{\prime}=1,5-3,5$ menunjukkan keanekaragaman jenis tergolong sedang, dan jika $H^{\prime}>3,5$ menunjukkan keanekaragaman tergolong tinggi. Berdasarkan hal tersebut maka plot klaster Resort Biha, Ngambur, dan Pemerihan menunjukkan tingkat keanekaragamannya tergolong sedang dengan nilai $H^{\prime}=1,5-3,5$ tetapi di klaster plot 12 (dua belas) Resort Pemerihan menunjukkan tingkat keanekaragamannya tergolong tinggi dengan nilai $\mathrm{H}^{\prime}>3,5$.

Berdasarkan Shannon-Whiener (Soerianegara dan Indrawan, 2005),jika nilai $\mathrm{H}^{\prime}<1$, maka komunitas vegetasi dengan kondisi lingkungan kurang stabil; jika nilai $\mathrm{H}^{\prime}$ antara 1-2, maka komunitas vegetasi dengan kondisi lingkungan stabil; jika nilai $\mathrm{H}^{\prime}>2$, maka komunitas vegetasi dengan kondisi lingkungan sangat stabil. Berdasarkan hal tersebut maka rata-rata klaster plot 
Resort Biha, Ngambur, dan Pemerihan menunjukkan komunitas vegetasi dengan kondisi lingkungan sangat stabil dengan nilai H'>2, hanya di klaster plot 13 (tiga belas) Resort Pemerihan menunjukkan komunitas vegetasi dengan kondisi lingkungan stabil dengan nilai $H^{\prime}=1-2$.

Keanekaragaman jenis pohon dapat dijadikan indikator peniliaian kesesehatan hutan kareana sensitif terhadap perubahan; indikator sistem ekologi; dan heterogenitas spasial, temporal, dan trofik. Biodiversitas sangat mudah dipengaruhi oleh lingkungan, interaksi antar organisme hidup, dan interaksi antar organisme dan lingkungannya. Perubahan yang terjadi disebabkan oleh respon positif atau negatif dari interaksi tersebut seperti contoh pertumbuhan, perkembangan, mortalitas, natalitas, dan migrasi. Setelah memperoleh nilai keanekaragaman jenis, dilakukan penentuan nilai skor pada masing-masing klaster plot. Disajikan pada Tabel 2.

Tabel 2. Nilai skor setiap parameter (indikator)

\begin{tabular}{cc}
\hline Nilai skor & Kelas keanekararagaman jenis $\left(\mathrm{H}^{\prime}\right)$ \\
\hline 1 & $1,55-1,77$ \\
2 & $1,78-2,00$ \\
3 & $2,01-2,23$ \\
4 & $2,24-2,45$ \\
5 & $2,46-2,68$ \\
6 & $2,69-2,91$ \\
7 & $2,92-3,13$ \\
8 & $3,14-3,36$ \\
9 & $3,37-3,59$ \\
10 & $3,60-3,82$
\end{tabular}

Nilai skor tertinggi yaitu 10 dengan nilai kelas keanekaragaman jenis 3,60-3,82. Sedangkan, nilai skor terendah 1 dengan nilai 1,55-1,77. Hal ini menunjukkan bahwa tinggi rendahnya nilai skor parameter indikator ekologis kesehatan hutan sangat berpengaruh terhadap nilai akhir kondisi kesehatan hutan. Semakin tinggi nilai skor menunjukkan tingkat kesehatan hutan semakin tinggi. Nilai akhir kesehatan hutan didapatkan dari perkalian antara nilai skor setiap klaster plot dengan nilai tertimbang. Hasil dari nilai akhir kesehatan hutan ditampilkan pada Tabel 3.

Tabel 3. Nilai ambang batas status kesehatan hutan konservasi

\begin{tabular}{cc}
\hline Kelas nilai akhir & $\begin{array}{c}\text { Kategori kondisi kesehatan hutan } \\
\text { konservasi }\end{array}$ \\
\hline $6,19-8,79$ & Bagus \\
$3,60-6,18$ & Sedang \\
$1,00-3,59$ & Jelek \\
\hline
\end{tabular}

Kategori kondisi kesehatan hutan diperoleh berdasarkan nilai akhir. Nilai akhir kesehatan hutan Resort Pemerihan TNBBS tertinggi sebesar 2,10 dan terendah 0,31 . Hasil kategori kondisi kesehatan hutan ini menunjukkan masih dibutuhkan perlakuan intensif untuk meningkatkan status kesehatan hutan di TNBBS. Status kesehatan hutan dihasilkan dari nilai akhir kesehatan hutan dan kategori kesehatan hutan. Ditampilkan berikut ini pada Tabel 4.

Tabel 4. Nilai akhir status kesehatan hutan konservasi

\begin{tabular}{ccc}
\hline $\begin{array}{c}\text { No. plot } \\
\text { klaster }\end{array}$ & $\begin{array}{c}\text { Nilai akhir } \\
\text { kondisi } \\
\text { kesehatan }\end{array}$ & $\begin{array}{c}\text { Kategori kondisi } \\
\text { kesehatan hutan } \\
\text { konservasi }\end{array}$ \\
\hline 1 & 7,60 & Bagus \\
2 & 8,03 & Bagus \\
3 & 4,02 & Sedang \\
4 & 3,80 & Sedang \\
5 & 7,06 & Bagus \\
6 & 5,45 & Sedang \\
7 & 5,40 & Sedang \\
8 & 5,78 & Sedang \\
9 & 4,57 & Sedang \\
10 & 5,00 & Sedang \\
11 & 7,24 & Bagus \\
12 & 8,79 & Bagus \\
13 & 1,00 & Jelek \\
\hline
\end{tabular}

Kondisi kesehatan hutan yang paling sehat terdapat pada klaster plot dua belas yang memiliki nilai akhir tertinggi yaitu 8,79 dengan kategori bagus. Sebaliknya, kondisi kesehatan hutan yang paling jelek terdapat pada klaster plot tiga belas yang memiliki nilai akhir terendah yaitu 1,00. Dari hasil data yang diperoleh dapat dikategorikan kondisi kesehatan hutan di TNBBS sedang sebanyak $54 \%$ bagus $38 \%$ sedang dan $8 \%$ jelek.

\section{KESIMPULAN}

Hasil penelitian menunjukkan bahwa nilai keanekaragaman kondisi pada saat ini (status) kesehatan hutan di TNBBS berada pada kriteria sedang $(3,60-6,18)$ sebesar $54 \%$, sehingga menunjukkan bahwa hutan TNBBS memiliki kondisi cukup sehat (stabil). Dengan demikian, kesehatan hutan konservasi dapat dinilai dengan indikator biodiversitas (keanekaragaman jenis pohon).

\section{UCAPAN TERIMA KASIH}

Terima kasih atas pendanaan penelitian Tim Pasca Sarjana dari Direktorat Riset dan Pengabdian Masyarakat 
dan Direktorat Jenderal Penguatan Riset dan Pengembangan Kementerian Riset, Teknologi dan Pendidikan Tinggi Republik Indonesia (Nomor: 062/SP2H/LT/DRPM/2018).

\section{DAFTAR PUSTAKA}

Balai Besar Taman Nasional Bukit Barisan Selatan. (2017). Profile TNBBS. Diakses pada 14 Maret 2017 dari http:/tnbbs.org/Profile/.

Kusmana, C., \& Hikmat, A. (2015). Keanekaragaman Hayati Flora di Indonesia. Jurnal Pengelolaan Sumberdaya Alam dan Lingkungan, 5(2): 187-198.

Magguran, A.E. (1988). Ecological Diversity and lts Measuement. USA: Princeton University Press.

Mangold, R. (1997). Forest Health Monitoring: Field Methods Guide. USDA Forest Service.
Nuhamara, S.T., Kasno, \& Irawan, U.S. (2001). Assessment on Damage Indicators in Forest Helath Monitoring to Monitor the Sustainability of Indonesian Tropical Rain Forest. Forest Health Monitoring to Monitor The Sustaainability of Indonesian Traopical Rain Forest. Volume II. Japan: ITTO dan Bogor (ID): SEAMEO_BIOTROP.

Odum, E.P. (1998). Dasar-dasar Ekologi: Terjemahan dari Fundamentals of ecology. Alih Bahasa Samingan, T. Edisi Ketiga. Yogyakarta: Universitas Gadjah Mada Press.

Safe'i, R., Hardjanto., Supriyanto., \& Sundawati, L. (2015). Pengembangan Metode Penilaian Kesehatan Hutan Rakyat Sengon. Jurnal Penelitian Hutan Tanaman, 13(3): 175-187.

Safe'i, R., \& Tsani, M.K. (2016). Penilaian Kesehatan Hutan Menggunakan Teknik Forest Health Monitoring. Kesehatan Hutan. plantaxia. Edisi Pertama. Yogyakarta. p102.

Soerianegara, I., \& Indrawan, A. (2005). Ekologi Hutan Indonesia. Bogor: Fakultas Kehutanan IPB.

WWF. (1989). The Importance of Biological Diversity. Switzerland: WWF, Gland. 